\title{
Consistent Comparison for The Linearity Air Kerma of IEC Standards and Commercial Load in Diagnosing DR Generators
}

\author{
Beomhui Han ${ }^{* * * *}$, Chongyeal Kim ${ }^{* * *}$, Sangho Lee*, Sanghyun Han, Ingyu You ${ }^{* *}$ \\ Dept. of Radiological Science, Seonam University ${ }^{*}$, Dept. of Dignostic Radiology, Hallym University Hospital ${ }^{* *}$, \\ Dept. of Radiarion Science \& Technology, Chonbuk National University ${ }^{* * *}$
}

\section{진단용 DR 발생장치에서 IEC 표준규격과 상용부하의 공기커마 직선성에 대한 일관성 비교}

\author{
한범희,***, 김종일**, 이상호*, 한상현 ${ }^{*}$, 유인규 ${ }^{* *}$ \\ 서남대학교 방사선학과*, 한림대학교병원 영상의학과**, 전북대학교 방사선과학기술학과***
}

\begin{abstract}
In this study, based on IEC 60601-2-54 standard load conditions presented in the limited interval over the air kerma at the absolute linearity closely evaluated by measuring the $\mathrm{X}$-ray results were as follows:

10 units targeted all Diagnostic X-ray generating device (DR) presented in the IEC 60601-2-54 standard linearity of air kerma emerged as inappropriate, the general evaluation of the dose linearity from four in the top $50 \%$ and $80 \mathrm{kVp} \%$ of the two measurement series were as irrelevant all the rest from six of the top tube voltage of $50 \%$ and $80 \%$ of the two measurement series, appeared in all suitable.

Presented in IEC 60601-2-54 standard dose linearity testing and conventional linearity tests showed many differences. IEC 60601-2-54 standard linearity in the proposed international standards of air kerma is the recommendation of the existing dose linearity considerably more feasible, and to quantify the amount of radiation as the standard suggested by the standard IEC 60601-2-54 air kerma of a diagnostic X-ray imaging device linearity performance management is considered key elements in the critical appraisal.
\end{abstract}

Key Words : Air Kerma, Linearity, IEC, Performance Management

\section{요야}

본 연구에서는 IEC 60601-2-54에서 제시한 표준을 근거로 부하조건에서의 제한된 간격으로 걸친 공기커마를 절 대측정하여 X선의 직선성을 면밀히 평가하여 다음과 같은 결과를 얻었다.

10 대를 대상으로 한 모든 진단용 X선 발생장치(DR)는 IEC 60601-2-54 표준에서 제시한 공기커마의 직선성이 부 적합으로 나타났고, 일반적인 조사선량의 직선성 평가방법에서는 4 대에서 최고 관전압의 $50 \%$ 와 $80 \%$ 의 두 개 측정 계 열 모두 부적합으로 나타났으며, 나머지 6 대에서는 최고 관전압의 $50 \%$ 와 $80 \%$ 의 두 개 측정 계열 모두에서 적합으로 나타났다. 
IEC 60601-2-54 표준에서 제시한 직선성 시험과 기존의 조사선량 직선성 시험이 많은 차이를 보였다. IEC 60601-2-54 표준+에서 제시한 공기커마의 직선성은 국제표준의 권고사항이므로 기존의 조사선량 직선성 보다 상당 히 타당성이 있고, 방사선량을 정량화하기 위한 표준으로 IEC 60601-2-54 표준에서 제시한 공기커마의 직선성이 진 단용 X선 영상장치 성능관리에 중요한 평가 요소라 사료된다.

중심단어 : 공기카마, 직선성, $\mathrm{IEC}$, 성능관리

\section{I. 서론}

우리나라의 진단용 $\mathrm{X}$ 선발생장치에 관한 품질관리 는 제조품질관리와 사용자품질관리로 나누어 이루어 지고 있다. 제조품질관리 규격에 의해 안전하게 제조 된 진단용 $\mathrm{X}$ 선발생장치는 병원에 설치된 후에도 제조 당시의 품질이 그대로 유지되기 위하여 인수시험에 이어 현상시험이 이루어져야 하며, 이어서 사용자품질 관리(일관성시험)가 이루어져야 한다. 요즘은 $\operatorname{IEC(ㄱㅜㄱㅈㅔ~}$ 전기기술위원회)규격을 그대로 자국의 규격으로 발표 하는 국가들이 많아졌으며 우리나라도 IEC규격을 그 대로 $\mathrm{KS}$ 화하고 있다 ${ }^{[1]}$. IEC에서는 제품의 개발설계 단 계에서 리스크 평가와 그 평가에 따른 안전대책을 실 시하는, 즉, 제품의 개발 단계부터 특정 안전규제나 안 전기준의 적합성과 함께 리스크 평가를 기초로 원천 적이고 종합적인 안전대책을 수립하는 안전경영시스 템을 규격화하고 있다. 동시에 기계의 한계결정, 위험 의 인식, 리스크 예측, 리스크 감정 등의 제반 리스크 평가방법을 표준화하고 있다 ${ }^{[2]}$. 그 중에서 IEC 60601-2-54는 의료용 전기기기의 표준이며, 촬영 및 투 시용X선 장치의 기본안전과 필수성능에 관한 개별 요 구사항에 대해 규정하고 있다. 진단용 X선 발생장치의 성능은 관전압과 관전류 및 조사시간에 따라 결정되 며, 이것은 X선에 의한 화질로 연결된다. 화질은 $\mathrm{X}$ 선 장치의 출력과 선질, 재현성(reproducibility) 및 직선성 (linearity) 등에 의해서 좌우되며, 이러한 요소는 장시간 사용 시에도 연속적으로 그 특성이 재현될 수 있어야 한다 ${ }^{[3]}$. 특히, $\mathrm{X}$ 선의 직선성은 출력량의 일정한 정도를 나타내는 것으로 화질 구현에 중요한 평가 요소이다. $\mathrm{X}$ 선 촬영에서 발생하는 $\mathrm{X}$ 선의 총 선량은 관전압이 일 정할 때 관전류량 $(\mathrm{mAs})$ 에 비례하며, 일정한 $\mathrm{mAs}$ 에 대 하여 관전류와 조사시간을 여러 형태로 바꿀 수 있다.
따라서 관전류와 조사시간이 변화되어도 $\mathrm{mAs}$ 가 일정 하면 X선량은 항상 일정하여야 한다. 그리고 조사시간 또는 관전류의 일정한 변화에 대하여도 발생하는 X선 량 또한 일정하게 변화되어야 한다 ${ }^{[4]}$. 이러한 X선의 직선성 평가는 연속적으로 검사하는 일반촬영검사, 투 시 및 혈관조영검사에서 $\mathrm{X}$ 선 발생장치의 출력선량을 평가하는 중요한 기준이 되고 있다. IEC 60601-2-54표 준에서 제시하는 직선성은 $\mathrm{mAs}$ 값을 상당히 낮게 유지 하고 평가하는 시험으로 검증하고 있다. 또한, $\mathrm{X}$ 선 진 단에 의한 방사선량을 정량화하기 위해서는 방사선량 을 가늠할 수 있는 표준이 필요하다. $\mathrm{X}$ 선 방사선량을 나타내는 물리량은 공기커마이며, 한국표준과학연구 원에서는 국가측정표준대표기관으로서 X선 공기커마 국가표준을 확립하여 유지하고 있다. X선 공기커마 측 정표준은 자유공기전리함을 이용한 절대측정 방법으 로 이용되고 있으며, 이를 바탕으로 최근 지식경제부 산하 기술표준원에서는 의료용 전기기기 기본안전 및 필수성능의 표준을 제정하였다. 이 표준은 촬영 및 투 시 목적으로 사용하는 의료용 전기기기에 대해 성능 평가의 표준을 규정함으로써 측정표준의 국제적 동등 성을 확보하도록 하였다 ${ }^{[5]}$.

본 연구에서는 IEC 60601-2-54에서 제시한 표준을 근거로 부하조건에서의 제한된 간격으로 걸친 공기커 마를 절대측정하여 $\mathrm{X}$ 선의 직선성을 면밀히 평가함으 로써, 공기커마의 직선성이 영상장치의 성능관리에 중 요한 요소임을 입증하고자 한다.

\section{II. 실험 및 방법}

\section{1. 실험기기}

최고 관전압이 $150 \mathrm{kVp}$ 인 Digital Radiography 장치 [Fig. 1] 10대와 Ion Chamber 60cc(Model 2026C)[Fig. 2]를 
비롯한 줄자, 테이프 등을 이용하여 IEC 60601-2-54에 서 제시한 표준을 근거로 부하조건에서의 제한된 간 격으로 걸친 공기커마의 직선성을 측정하였다.

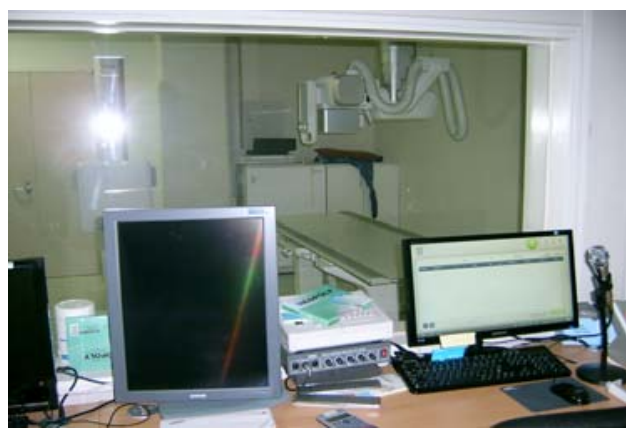

Fig. 1 Digital Radiography Device

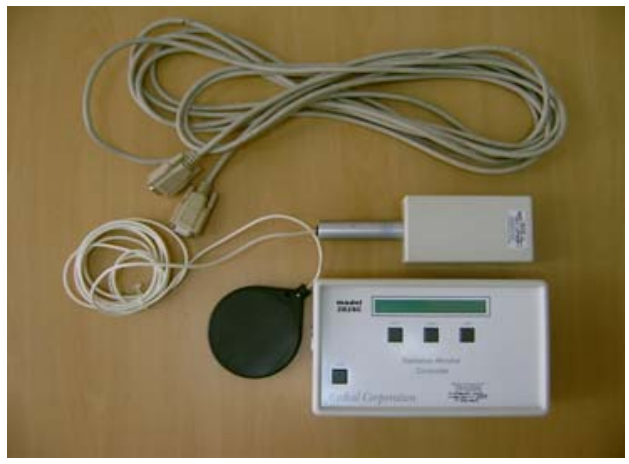

Fig. 2 Ion Chamber

\section{2. 실험방법}

IEC 60601-2-54에서 제시한 표준을 근거로 부하 조 건의 제한된 간격에 걸친 공기커마의 직선성 시험 방 법은 $\mathrm{X}$ 선발생장치의 관전압 최고치의 $50 \%$ 와 $80 \%$ 의 두 개 측정 계열에서 전류 시간 곱 $(\mathrm{mAs})$ 이 $1 \mu \mathrm{Gy}$ 에서 5 $\mu \mathrm{Gy}$ 사이의 인가출력량과 부하시간이 모든 설정에 대 하여 0.01 초와 0.032 초 사이 영역에서 변화하여 10 회 측정한다. 최고 관전압이 $150 \mathrm{kVp}$ 인 진단용 $\mathrm{X}$ 선발생장 치 총 10 대를 이용하여 FFD를 $100 \mathrm{~cm}$ 로 하고, 조사야 크기를 $15 \times 15 \mathrm{~cm}$ 로 조정한다[Fig. 3]. 공기커마의 평균 값을 계산하고 아래의 공식에 의해 적합한가를 검증 한다.

$$
\left|\frac{\overline{K_{1}}}{Q_{1}}-\frac{\overline{K_{2}}}{Q_{2}}\right| \leq 0.2 \frac{\overline{K_{1}}+\frac{\overline{K_{2}}}{Q_{2}}}{2}
$$

여기서 $\overline{K_{1}}, \overline{K_{2}}$ 은 공기커마 측정값의 평균이며, $Q_{1}, Q_{2}$ 는 표시된 $\mathrm{mAs}$ 이며, 변동계수의 평균값은 0.2 배 이상 차이가 나서는 안 된다 ${ }^{[6]}$.

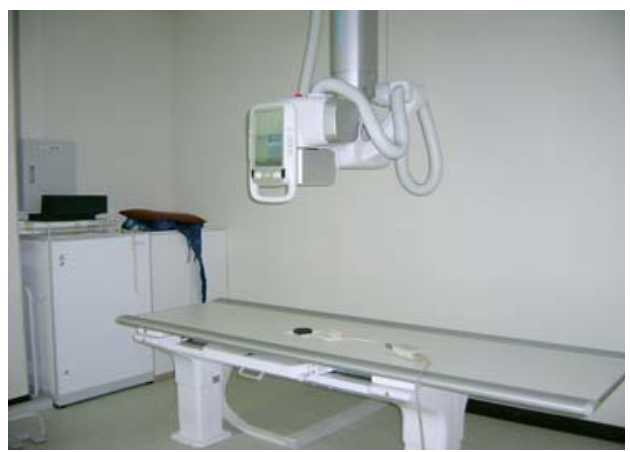

Fig. 3 Linearity Test

위와 같은 실험이 일반적인 실험방법이 아니기 때 문에 동일한 조건하에서 일반적인 조사선량의 직선성 평가방법과 비교하여 분석하였다.

$$
\frac{X_{1}-X_{2}}{X_{1}+X_{2}} \leq 0.1
$$

여기서 $X_{1}, X_{2}$ 은 각각 최고치의 평균 $/ \mathrm{mAs}$ 와 최저 치의 평균 $/ \mathrm{mAs}$ 이고, 변동계수는 조사선량인 경우 0.1 이하가 되어야 한다.

\section{III. 실험결과}

최고 관전압 $150 \mathrm{kVp}$ 인 10 대의 Digital Radiography 발 생장치의 IEC 60601-2-54에서 제시한 직선성을 평가한 결과 모든 장치에서 부적합으로 나타났다[Table 1]. 
Table 1. IEC 60601-2-54에서 제시한 직선성

\begin{tabular}{|c|c|c|c|c|c|c|}
\hline $\begin{array}{l}\text { Equip } \\
\text { ment }\end{array}$ & $\mathrm{kVp}$ & $\mathrm{mA}$ & Time & $\begin{array}{l}\text { Aver age } \\
\text { dose(mR) }\end{array}$ & Linear ity & $\begin{array}{l}\text { Evalu } \\
\text { ation }\end{array}$ \\
\hline \multirow[b]{2}{*}{ A } & 75 & 25 & 0.025 & 36.89 & 46.77 & \multirow[b]{2}{*}{$\times$} \\
\hline & 120 & 25 & 0.01 & 26.44 & $\begin{array}{c}\not \leq \\
16.48\end{array}$ & \\
\hline \multirow[b]{2}{*}{ B } & 75 & 50 & 0.016 & 38.60 & 63.98 & \multirow[b]{2}{*}{$\times$} \\
\hline & 120 & 50 & 0.01 & 55.75 & $\begin{array}{c}\not \\
15.98\end{array}$ & \\
\hline \multirow[b]{2}{*}{ C } & 75 & 80 & 0.0125 & 35.09 & 82.29 & \multirow[b]{2}{*}{$\times$} \\
\hline & 120 & 50 & 0.01 & 58.69 & $\begin{array}{c}\not \leq \\
15.25\end{array}$ & \\
\hline \multirow[b]{2}{*}{ D } & 75 & 75 & 0.015 & 35.80 & 71.78 & \multirow[b]{2}{*}{$\times$} \\
\hline & 120 & 10 & 0.015 & 15.54 & $\begin{array}{c}\not \leq \\
13.54\end{array}$ & \\
\hline \multirow[b]{2}{*}{$E$} & 75 & 16 & 0.03125 & 30.69 & 113.52 & \multirow[b]{2}{*}{$x$} \\
\hline & 120 & 10 & 0.01 & 17.49 & $\begin{array}{c}\not 士 \\
23.49\end{array}$ & \\
\hline \multirow[b]{2}{*}{$\mathrm{F}$} & 75 & 25 & 0.032 & 46.68 & 103.1 & \multirow[b]{2}{*}{$\times$} \\
\hline & 120 & 10 & 0.01 & 16.14 & $\begin{array}{c}\not \\
21.98\end{array}$ & \\
\hline \multirow[b]{2}{*}{ G } & 75 & 25 & 0.032 & 40.44 & 158.65 & \multirow[b]{2}{*}{$x$} \\
\hline & 120 & 10 & 0.01 & 20.92 & $\begin{array}{c}\not \leq \\
25.98 \\
\end{array}$ & \\
\hline \multirow[b]{2}{*}{$H$} & 75 & 20 & 0.025 & 31.79 & 136.37 & \multirow[b]{2}{*}{$x$} \\
\hline & 120 & 10 & 0.02 & 39.99 & $\begin{array}{c}\not \leq \\
26.35\end{array}$ & \\
\hline \multirow[b]{2}{*}{1} & 75 & 50 & 0.012 & 46.63 & 125.6 & \multirow[b]{2}{*}{$\times$} \\
\hline & 120 & 10 & 0.025 & 50.83 & $\begin{array}{c}\not \leq \\
28.1\end{array}$ & \\
\hline \multirow[b]{2}{*}{$J$} & 75 & 32 & 0.0125 & 48.57 & 77.53 & \multirow[b]{2}{*}{$\times$} \\
\hline & 120 & 10 & 0.02 & 39.79 & $\begin{array}{c}\not{X} \\
32.04\end{array}$ & \\
\hline
\end{tabular}

그러나 일반적인 조사선량의 직선성 평가에서는 4 대의 장비 $\mathrm{A}, \mathrm{B}, \mathrm{C}, \mathrm{D}$ 에서 최고 관전압의 $50 \%$ 와 $80 \%$ 의 두 개 측정 계열 모두 부적합으로 나타났고, 나머 지 6 대의 장비 $\mathrm{E}, \mathrm{F}, \mathrm{G}, \mathrm{H}, \mathrm{I}, \mathrm{J}$ 에서 최고 관전압의 $50 \%$ 와 $80 \%$ 의 두 개 측정 계열 모두에서 적합으로 나타났 다[Table 2].

Table 2. 상용부하의 직선성

\begin{tabular}{|c|c|c|c|c|c|c|c|}
\hline $\begin{array}{l}\text { Equip } \\
\text { ment }\end{array}$ & $k V p$ & $\mathrm{~mA}$ & Time & $\begin{array}{c}\text { Avera } \\
\text { ge } \\
\text { dose } \\
\text { (mR) }\end{array}$ & $\begin{array}{l}\mathrm{mR} / \\
\mathrm{mAs}\end{array}$ & $\begin{array}{c}\text { Linea } \\
\text { rity }\end{array}$ & $\begin{array}{l}\text { Evalı } \\
\text { at ior }\end{array}$ \\
\hline \multirow{6}{*}{ A } & \multirow{3}{*}{75} & 25 & 0.025 & 35.2 & 55.873 & \multirow{3}{*}{$\begin{array}{c}0.3 \not \leq \\
0.1\end{array}$} & \multirow{3}{*}{$x$} \\
\hline & & 75 & 0.0084 & 21.18 & 33.619 & & \\
\hline & & 100 & 0.0063 & 15.48 & 24.571 & & \\
\hline & \multirow{3}{*}{120} & 10 & 0.025 & 23.35 & 93.4 & \multirow{3}{*}{$\begin{array}{c}0.2 \nless \\
0.1\end{array}$} & \multirow{3}{*}{$x$} \\
\hline & & 25 & 0.01 & 25.7 & 102.8 & & \\
\hline & & 50 & 0.005 & 16.86 & 67.44 & & \\
\hline
\end{tabular}

\begin{tabular}{|c|c|c|c|c|c|c|c|}
\hline \multirow{6}{*}{ B } & \multirow{3}{*}{75} & 25 & 0.032 & 53.08 & 66.35 & \multirow{3}{*}{ 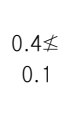 } & \multirow{3}{*}{$x$} \\
\hline & & 100 & 0.008 & 27.24 & 34.05 & & \\
\hline & & 200 & 0.004 & 11.89 & 14.862 & & \\
\hline & \multirow{3}{*}{120} & 10 & 0.05 & 42.8 & 85.6 & \multirow{3}{*}{$\begin{array}{c}0.2 \not \\
0.1\end{array}$} & \multirow{3}{*}{$x$} \\
\hline & & 25 & 0.02 & 60.98 & 121.96 & & \\
\hline & & 50 & 0.01 & 53.76 & 107.52 & & \\
\hline \multirow{6}{*}{ C } & \multirow{3}{*}{75} & 10 & 0.1 & 31.47 & 31.47 & \multirow{3}{*}{$\begin{array}{c}0.2 \not \\
0.1\end{array}$} & \multirow{3}{*}{$x$} \\
\hline & & 50 & 0.02 & 57.9 & 57.9 & & \\
\hline & & 100 & 0.01 & 40.44 & 40.44 & & \\
\hline & \multirow{3}{*}{120} & 25 & 0.02 & 60.78 & 121.56 & \multirow{3}{*}{$\begin{array}{c}0.3 \not 千 \\
0.1\end{array}$} & \multirow{3}{*}{$x$} \\
\hline & & 50 & 0.01 & 54.36 & 108.72 & & \\
\hline & & 100 & 0.005 & 28.54 & 57.08 & & \\
\hline \multirow{6}{*}{0} & \multirow{3}{*}{75} & 75 & 0.015 & 35.84 & 31.86 & \multirow{3}{*}{$\begin{array}{c}0.2 \not 丈 \\
0.1\end{array}$} & \multirow{3}{*}{$x$} \\
\hline & & 50 & 0.0225 & 38.32 & 34.06 & & \\
\hline & & 100 & 0.01125 & 22.51 & 20.00 & & \\
\hline & & 10 & 0.015 & 15.57 & 103.8 & & \\
\hline & 120 & 25 & 0.006 & 8.45 & 56.33 & 0.47 & $x$ \\
\hline & & 50 & 0.003 & 2.91 & 19.4 & & \\
\hline & & 16 & 0.03125 & 30.36 & 60.72 & & \\
\hline & 75 & 20 & 0.025 & 30.6 & 61.2 & $\begin{array}{l}0.01 \\
<01\end{array}$ & 0 \\
\hline$F$ & & 50 & 0.01 & 31.28 & 62.56 & & \\
\hline$E$ & & 10 & 0.01 & 17.52 & 206.6 & & \\
\hline & 120 & 12.5 & 0.008 & 15.64 & 156.4 & $\begin{array}{l}0.00 \\
<01\end{array}$ & 0 \\
\hline & & 16 & 0.00625 & 16.51 & 165.1 & & \\
\hline & & 25 & 0.032 & 46.52 & 58.15 & & \\
\hline & 75 & 32 & 0.025 & 46.38 & 57.98 & $<0$ & 0 \\
\hline$F$ & & 40 & 0.02 & 46.20 & 57.75 & & \\
\hline$r$ & & 10 & 0.01 & 16.0 & 160.0 & & \\
\hline & 120 & 12.5 & 0.008 & 16.26 & 162.6 & $\begin{array}{l}0.008 \\
<01\end{array}$ & 0 \\
\hline & & 20 & 0.005 & 16.20 & 162.0 & & \\
\hline & & 25 & 0.032 & 40.42 & 50.53 & & \\
\hline & 75 & 32 & 0.025 & 40.94 & 51.2 & $\begin{array}{l}0.006 \\
<01\end{array}$ & 0 \\
\hline C & & 80 & 0.01 & 40.90 & 51.13 & & \\
\hline$G$ & & 10 & 0.01 & 20.8 & 208.0 & & \\
\hline & 120 & 25 & 0.004 & 20.84 & 208.4 & $\begin{array}{l}0.01 \\
<0.1\end{array}$ & 0 \\
\hline & & 50 & 0.002 & 20.34 & 203.4 & & \\
\hline & & 20 & 0.025 & 31.78 & 63.56 & & \\
\hline & 75 & 25 & 0.02 & 31.72 & 63.44 & $\begin{array}{l}0.005 \\
<01\end{array}$ & 0 \\
\hline$H$ & & 50 & 0.01 & 31.46 & 62.92 & & \\
\hline$\Pi$ & & 10 & 0.02 & 38.26 & 191.3 & & \\
\hline & 120 & 20 & 0.01 & 38.64 & 193.2 & $\begin{array}{l}0.005 \\
<0.1\end{array}$ & 0 \\
\hline & & 25 & 0.008 & 38.44 & 192.2 & & \\
\hline & & 12.5 & 0.048 & 54.76 & 91.27 & & \\
\hline & 75 & 25 & 0.024 & 55.30 & 92.17 & $\begin{array}{l}0.08 \\
<01\end{array}$ & 0 \\
\hline 1 & & 50 & 0.012 & 46.66 & 77.77 & & \\
\hline 1 & & 10 & 0.025 & 50.74 & 202.96 & & \\
\hline & 120 & 12.5 & 0.02 & 50.00 & 200.00 & $\begin{array}{l}0.03 \\
<01\end{array}$ & 0 \\
\hline & & 25 & 0.01 & 48.02 & 192.08 & & \\
\hline & & 12.5 & 0.032 & 43.04 & 107.6 & & \\
\hline & 75 & 25 & 0.016 & 47.26 & 118.15 & $\begin{array}{l}0.06 \\
<0.1\end{array}$ & 0 \\
\hline 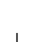 & & 32 & 0.0125 & 48.78 & 121.95 & & \\
\hline 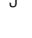 & & 10 & 0.02 & 42.2 & 211.0 & & \\
\hline & 120 & 12.5 & 0.016 & 42.66 & 213.3 & $\begin{array}{l}0.02 \\
\leq 0.1\end{array}$ & 0 \\
\hline & & 16 & 0.0125 & 41.38 & 206.9 & & \\
\hline
\end{tabular}




\section{$\mathrm{IV}$. 고찰}

진단용 X선 발생장치에 관한 품질관리는 제조품질 관리에 속하는 인수시험과 현상시험이 있고, 사용자품 질관리에 속하는 일관성시험이 있다. 인수시험은 기기 가 계약한 사양이 적합한지 아닌지를 사용자와 제조 업자가 장치를 도입할 때 실시한다. 현상시험은 평상 시에 설비의 성능상태를 확인하기 위해 실시한다. 결 과가 합격인 경우에는 일관성시험의 기초데이터로 사 용하고, 결과가 불합격인 경우에는 시정조치를 한 후 다시 한 번 현상시험을 한다. 일관성시험은 사용자가 기기의 성능이 설정기준을 만족하고 있는가를 확인하 고, 기기의 성능열화를 조기에 발견하기 위해 실시하 는 일련의 시험이며, 간단하고 신속한 방법으로 기기 의 성능의 불변성을 감시하는 것을 목적으로 하고 있 다. 식품의약품안전청이 1995년 제정한 “진단용 방사 선 발생장치의 안전관리에 관한 규칙"의 내용은 제정 당시부터 $\operatorname{IEC}$ (국제전기기술위원회)의 규격과 CFR 21, $\mathrm{JIS}$ 를 참고하여 만들었으며, 이를 바탕으로 개정되어 왔다 ${ }^{[1]}$.

IEC는 전기 및 전자분야에서 규격에 대한 준수 확 인 등과 같은 표준화에 대한 제반 현안 및 관련사항에 대한 국제간 협력을 촉진하여 국제간의 이해를 증진 시키고, IEC규격의 형식을 간행물로 발행하여 권고함 으로써 각국의 국가 규격에 반영시키는 것을 목적으 로 하고 있다 ${ }^{[2]}$. 우리나라는 1999년 이후로 기술표준원 (KATS)이 담당하여 IEC권고사항을 발표하고 있다 ${ }^{[7]}$. IEC 60601 표준에서 의료용 전기기기-제2-54부는 촬영 및 투시용X선장치의 기본안전과 필수성능에 관한 개 별요구사항으로서 의료용 전기기기의 시스템을 중재 및 응용할 의도로 사용하는 표준이다.

본 연구에서는 IEC 60601-2-54에서 제시한 공기커마 의 직선성 시험이 지금까지 사용한 조사선량의 직선 성 평가 방식과 다르기 때문에 기존의 방식과 비교하 여 분석하였다.

최고 관전압 $150 \mathrm{kVp}$ 인 10 대의 Digital Radiography 발 생장치의 IEC 60601-2-54에서 제시한 직선성을 평가한 결과 모든 장치에서 부적합으로 나타났으며, 기존 조 사선량의 직선성 연구에서는 진단용 $\mathrm{X}$ 선 발생장치
(DR) 4대에서 직선성의 평가가 부적합으로 나타났고, 나머지 6대는 적합으로 나타났다. 일반적인 방식으로 시험 한 조사선량의 직선성 평가를 연구한 논문을 살 펴보면 황춘성의 X-선 발생장치의 출력특성에 관한 연구에서는 단상전파정류장치 및 3 상전파정류장치와 인버터장치의 직선성 비교에서 인버터장치가 가장 안 정하게 나타났고 ${ }^{[8]}$, 강병삼 외의 수도권지역 일반촬영 장비의 정도관리 분석에서는 종합병원의 장비 28 대 모 두에서 직선성이 적합으로 나타났다 ${ }^{[9]}$. 이는 대관전류 영역에서 측정 평가한 것으로 본 연구와 차이가 있다. 또한 권덕문의 진단용 $\mathrm{X}$ 선 장치의 출력특성 분석 및 콜리메이터 성능개선의 논문에서 저관전압, 대관전류 에서 직선성이 양호하게 나타났다 ${ }^{[10]}$ 는 내용은 본 연 구와 비교하기엔 무리가 있는 것으로 사료된다. 이와 같이 동일한 조건과 $\mathrm{DR}$ 장비를 대상으로 한 논문이 적 어 객관적 지표로 비교 분석하기에 부족한 면이 있는 것과, 조사시간이 0.01 초와 0.032 초 사이 영역에서 변 화하여 출력선량이 $1 \mu \mathrm{Gy}$ 에서 $5 \mu \mathrm{Gy}$ 사이에 나타나는 장비가 흔치 않았다는 점에서 제약이 따랐다.

본 연구에서 근거로 제시한 IEC 60601-2-54 표준을 적용하여 공기커마의 직선성을 평가하는 시험은 제조 품질관리에 속하는 인수시험에 해당하며 현재 이 시 험이 현상시험과 일관성시험에서 동일하지도 않고, 연 속적으로 이루어지지도 않고 있다. 앞으로 임상에서는 정기적으로 IEC 60601-2-54 표준을 사용자 품질관리의 일관성시험과 동일하게 적용하여 환자의 피폭저감을 위한 노력이 필요하리라 사료된다.

\section{$\mathrm{V}$. 결론}

진단용 X선 발생장치(DR) 10 대에서 IEC 60601-2-54 표준에서 제시한 공기커마의 직선성 시험을 평가한 결과 다음과 같은 결론을 얻었다.

모든 진단용 X선 발생장치(DR)에서 IEC 60601-2-54 표준에서 제시한 공기커마의 직선성이 부적합으로 나 타났으며, 일반적인 조사선량의 직선성 평가방법에서 는 4대에서 최고 관전압의 $50 \%$ 와 $80 \%$ 의 두 개 측정 계열 모두 부적합으로 나타났고, 나머지 6대에서는 최 고 관전압의 $50 \%$ 와 $80 \%$ 의 두 개 측정 계열 모두에서 적합으로 나타났다. IEC 60601-2-54 표준에서 제시한 
직선성 시험과 일반적인 조사선량의 직선성에서 많은 차이가 보였다. 이는 제조회사마다 국제표준을 따르지 않고 각자의 방식으로 기기를 측정하여 평가하며, IEC 60601-2-54 표준에서 제공된 공기커마의 직선성 평가 방법이 낮은 선량에서 평가하는 방식으로 적용하기 때문이다. IEC 60601-2-54 표준에서 제공된 표준방식으 로 측정한 공기커마의 직선성은 국제표준의 권고사항 이므로 기존의 조사선량 직선성 보다 상당히 타당성 이 있고, 방사선량을 정량화하기 위한 표준으로 IEC 60601-2-54에서 제시한 공기커마의 직선성이 진단용 X 선 영상장치 성능관리에 중요한 평가 요소임을 인식 해야 한다.

\section{Reference}

[1] 김정민, 진단용 엑스선장치의 주기적 성능관리 방안. 식품의약품안전청, 방사선 보건 Newletter, Vol. 19, No. 1, pp.15, 2012.

[2] .IEC 국제기구, http://www.iec.ch

[3] 윤정섭, 김춘식, 고신관, 의료용 $\mathrm{X}$ 선장치의 유지 및 성능관리에 관한 검토. 대한방사선기술학회지, Vol. 15 , No. 1, pp.25-26, 1992.

[4] 강세식 외 : 진단용 영상장치 정도관리 실험. 청구문화사, 2010, 개정2판

[5] 이철영, 진단 $\mathrm{X}$-선 공기커마 일차표준기 특성평가 연구. 한국표준과학연구원 연구보고서. pp.6, 2008

[6] 의료용 전기기기-제2-54부 : 촬영 및 투시용X선장치의 기본안전과 필수성능에 관한 개별요구사항. 지식경제부 기술표준원. 2012

[7] 산업자원부 기술표준원, http://standard.ats.go.kr

[8] 황춘성, X-선 발생장치의 출력특성에 관한 연구. 조선대학교 산업대학원 전기공학과, 석사학위논문, pp.33-35, 1999

[9] 강병삼 외, 수도권지역 일반촬영 장비의 정도관리 분석. 방사선기술과학회지, Vol. 35, No. 2, pp.93-101, 2012.

[10] 권덕문 : 診斷用 X線 裝置의 出力特性 分析 및 콜리메이터 性能改善. 영남대학교 대학원 센서 및 시스템공학과 박사학위논문, pp.57-59, 2002 